OPEN ACCESS

Edited by:

José Roberto Mineo,

Federal University of Uberlandia, Brazi

Reviewed by:

Jorge Enrique Gómez Marín,

University of Quindío, Colombia

Veeranoot Nissapatorn

Walailak University, Thailand

*Correspondence:

Dolores Correa

mariado/@yahoo.com

${ }^{\dagger}$ Present Address:

Yevel Flores-García,

Department of Molecular Microbiology and Immunology, Malaria Research Institute, Johns Hopkins Bloomberg School of Public Health, Baltimore,

MD, United States

Specialty section

This article was submitted to Microbial Immunology,

a section of the journal

Frontiers in Immunology

Received: 05 August 2018 Accepted: 04 February 2019 Published: 21 February 2019

Citation:

Gómez-Chávez F, Cañedo-Solares I, Ortiz-Alegría LB, Flores-García Y, Luna-Pastén H, Figueroa-Damián $R$, Mora-González JC and Correa D (2019) Maternal Immune Response During Pregnancy and Vertical Transmission in Human Toxoplasmosis.

Front. Immunol. 10:285 doi: 10.3389/fimmu.2019.00285

\section{Maternal Immune Response During Pregnancy and Vertical Transmission in Human Toxoplasmosis}

\author{
Fernando Gómez-Chávez ${ }^{1,2}$, Irma Cañedo-Solares ${ }^{1}$, Luz Belinda Ortiz-Alegría ${ }^{1}$, \\ Yevel Flores-García ${ }^{1 \dagger}$, Héctor Luna-Pastén ${ }^{1}$, Ricardo Figueroa-Damián ${ }^{3}$, \\ Juan Carlos Mora-González ${ }^{4}$ and Dolores Correa ${ }^{\text {t* }}$
}

${ }^{1}$ Laboratorio de Inmunología Experimental, Instituto Nacional de Pediatría, Secretaría de Salud, Mexico City, Mexico, ${ }^{2}$ Cátedras CONACyT-Instituto Nacional de Pediatría, Mexico City, Mexico, ${ }^{3}$ Servicio de infectología e Inmunología, Instituto Nacional de Perinatología, Mexico City, Mexico, ${ }^{4}$ Centro de Salud Gustavo A. Rovirosa, Secretaría de Salud, Mexico City, Mexico

Toxoplasmosis is a parasitic zoonosis distributed worldwide, caused by the ingestion of contaminated water/food with the parasite Toxoplasma gondii. If a pregnant woman is infected with this parasite, it may be transmitted to the fetus and produce ocular, neurological, or systemic damage with variable severity. The strength and profile of mother's immune response have been suggested as important factors involved in vertical transmission rate and severity of clinical outcome in the congenitally infected fetus. The aim of this work was to evaluate a possible relation between the mother's immune response during pregnancy and congenital transmission to the fetus. We obtained peripheral blood from $T$. gondii infected pregnant woman and tested it for anti T. gondii (lgG1, IgG2, IgG3, IgG4, and lgA) in serum. Peripheral blood mononuclear cells (PBMCs) were isolated to analyze the in vitro effect of soluble $T$. gondii antigens on proliferation and production of cytokines. We found that lgG2-4 and IgA antibodies and lymphocytes proliferation, especially $\mathrm{CD} 4^{+}, \mathrm{CD}^{+}$, and $\mathrm{CD} 19^{+}$were positive in a higher proportion of cases in transmitter than in non-transmitter women. Furthermore, IgG2-3 and IgA anti-Toxoplasma antibody levels were higher in those mothers who transmitted the infection than in those who did not. Interestingly, a higher proportion of positive cases to IFN- $\gamma$ and negatives to the immunoregulatory cytokine TGF- $\beta$, were related to $T$. gondii vertical transmission. Our descriptive results are consistent with the paradoxical previous observations in murine models of congenital toxoplasmosis, which suggest that an increased immune response that protects the mothers from a disseminated or severe disease, and should protect the fetus from infection, is positively related to parasite transmission.

Keywords: Toxoplasma gondii, human congenital toxoplasmosis, vertical transmission, cellular response, IFN- $\gamma$, TGF- $\beta 1$, IgG subclasses, IgA 


\section{INTRODUCTION}

Toxoplasma gondii is a foodborne pathogen which infects approximately one-third of all humans (1). Most individuals with toxoplasmosis show no clinical signs, however immunodeficient and congenitally infected patients may develop pathological conditions (2).

Congenital infection occurs due to vertical transmission of $T$. gondii during pregnancy, and although it is usually asymptomatic and self-limited in the mother, if the fetus is infected, he/she may develop variable clinical features, such as spontaneous abortion, stillbirth, hydrocephalus, macro or microcephalus, cerebral calcifications, retinochoroiditis, and other ocular or central nervous system alterations, which can manifest even years later in life (3).

It is widely known that in immunocompetent individuals, such as pregnant women, a Th1-type immune response represents the main effective response against the parasite (4, 5). Although there are some reports about $T$. gondii infected mother's immunity during pregnancy, it's role in promoting or inhibiting congenital transmission has not been directly tested (6-10).

Other important players involved in the control of $T$. gondii during acquired infections, are human IgG subclasses predominantly IgG1- and their Fc receptors; importantly, specific IgG1 in infected mothers has been related to clinical problems in their congenitally infected babies; however, they were measured at delivery, when transmission already occurred (11).

Due to the lack of information about the specific lymphocyte populations, cytokines, and antibody subtypes induced by $T$. gondii in infected women during pregnancy and their relationship to vertical transmission, we performed the present study.

\section{MATERIALS AND METHODS}

\section{Ethical Aspects}

This work was carried out in accordance with the World Medical Association's Declaration of Helsinki. It contains partial results from the project 060/2011, approved by the Research and Research Ethics Boards of the Instituto Nacional de Pediatría (INP), Mexico City, Mexico; registered at the Office for Human Research Protection of the NIH (http://ohrp.cit. nih.gov/search/search.aspx) with numbers IRB00008064 and IRB00008065. It was also approved by the INP Committee of Laboratory Animal Use and Care; approval is available upon request. The Instituto Nacional de Perinatología (INPer) also approved the project (number 212250-02231). All participants signed an informed consent, which explicitly stated that it was of low risk, considering that clinical management was not modified for the protocol. All newborns were clinically managed at INP according to national and international standards. Biosafety measures were carefully followed, in order to avoid technician's contamination with the $T$. gondii strain used to prepare the antigen, by using a level II biohazard hood (Labconco Purifier Class II Biosafety Cabinet, Labconco
Corp., Kansas, MO) when working with the parasites. A wellcontrolled animal house is present at INP, where the mice are inoculated. In addition, to avoid, potentially contagious diseases (present in the women recruited), only trained personnel who wore gloves and face masks was authorized to take samples from patients.

\section{Parasite Antigen}

Toxoplasma gondii tachyzoites ( $\mathrm{RH}$ strain) were maintained in $\mathrm{BALB} / \mathrm{c}$ mice by intraperitoneal passages. Peritoneal exudates from 40 mice were harvested and washed twice $\left(720 \times \mathrm{g}, 10 \mathrm{~min}, 4^{\circ} \mathrm{C}\right)$ in $\mathrm{PBS}$ supplemented with a protease cocktail inhibitor $(10 \mathrm{mg} / \mathrm{ml}$ aprotinin, $50 \mathrm{~g} / \mathrm{ml}$ leupeptin, and $1.6 \mathrm{mmol} / \mathrm{L}$ phenylmethylsulfonyl fluoride). To prepare soluble $T$. gondii antigen (STAg), the parasite suspension was lysed by five sonication cycles $(60 \mathrm{~Hz}$ for $1 \mathrm{~min}$ each) on ice. After centrifugation $\left(10,000 \mathrm{~g}, 2 \mathrm{~h}, 4^{\circ} \mathrm{C}\right)$ supernatants were collected and sterilized by filtration through a $0.2 \mu \mathrm{m}$-pore size membrane (Corning Costar Corp., Cambridge, MA). The protein concentration was determined by Bradford (Quick Start ${ }^{\mathrm{TM}}$ Protein Assay, Bio-Rad laboratories, Hercules, CA) and aliquots were stored at $-80^{\circ} \mathrm{C}$ until use.

\section{Patients and Study Strategy}

From 1,083 pregnant women screened for toxoplasmosis, we recruited 11 of them who agreed to participate and met criteria for further analysis. They were patients of the "Instituto Nacional de Perinatología-Isidro Espinosa de los Reyes" (third level hospital) or the "Centro de Salud-Dr. Gustavo A. Rovirosa Pérez," at Mexico City, Mexico. These volunteers ranged in age from 18 to 38 years and most of them (73\%) were in the first half of pregnancy (Table 1). They had no diagnosis of other chronic or acute infection, or autoimmune disease according to the clinical profile records; none of them received any specific drug treatment at the sample collection time, but as soon as the diagnosis was confirmed, they were all treated up to delivery by standard schemes with spiramycin or pyrimethamine (1). All but one case (11, see Table 1) were screened by inhouse specific IgG-ELISA and confirmed by IgG and IgM western blot (WB). Then, the infection acute or subacute phase was supported by serological and molecular tests, i.e., seroconversion, increase of total IgG antibodies (abs) in serial samples, low IgG avidity test, and/or $B 1$ gene detection by qPCR; all these procedures had been standardized by us previously and described in detail elsewhere (11-14). To classify the mothers in non-transmitters or transmitters, we followed their gestations until delivery, and confirmed or discarded congenital infection by clinical and laboratory tests in their children, as previously reported (15). Briefly, the newborns were tested for IgM, IgA abs by ELISA; also, their WB IgG pattern was compared to that of their mothers in order to look for neo-antibodies; finally, qPCR was also performed. In one case (11, Table 1) diagnosis of congenital toxoplasmosis (CT) was confirmed by positive qPCR in the fetal blood taken through cordocentesis, due to suspicion of fetal infection at the hospital. All except one infected mother (case 11, Table 1) resulted positive to specific anti-Toxoplasma IgG in the 


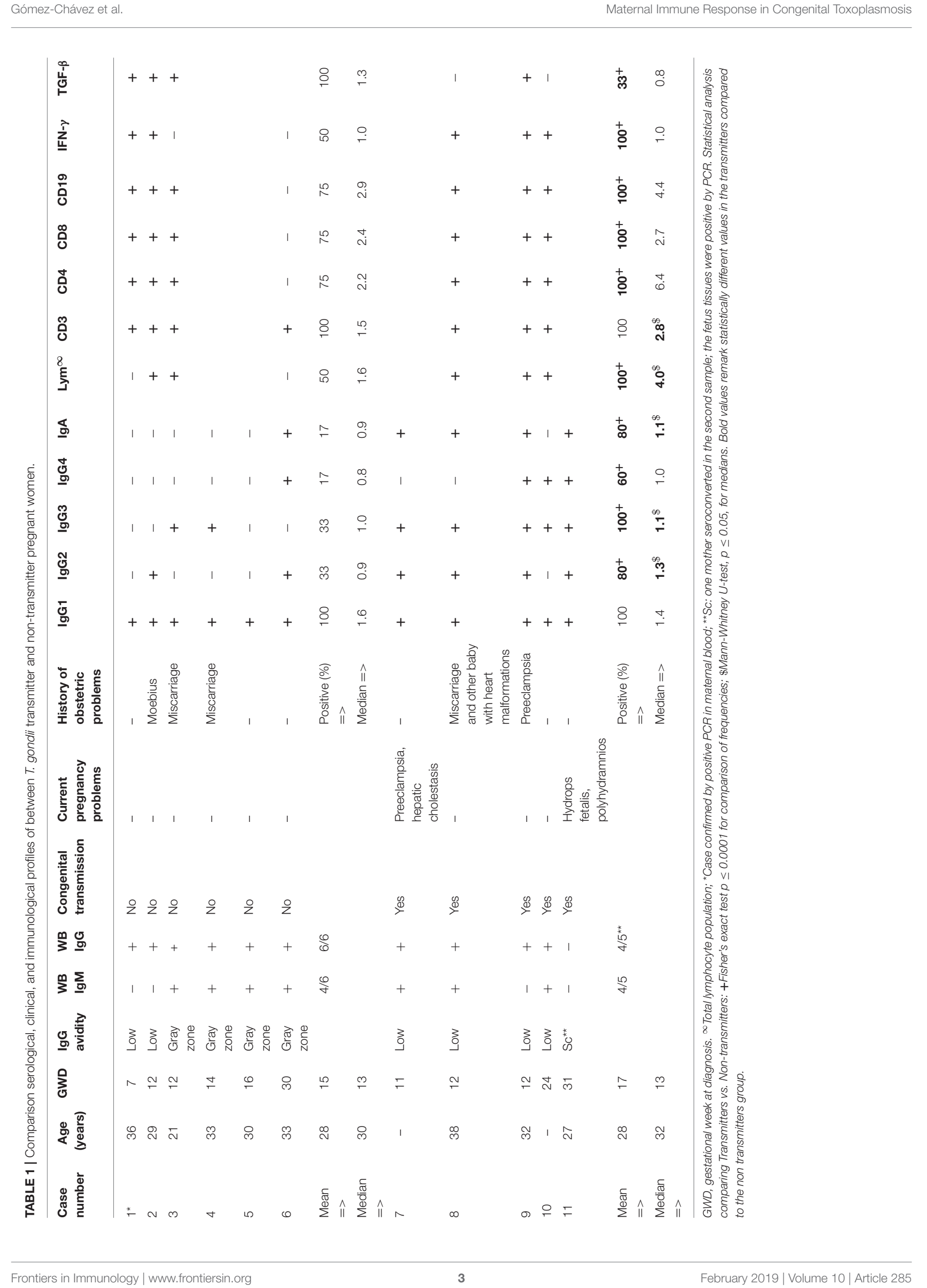


first sample by ELISA, while $80 \%$ of the non-transmitter and $66 \%$ of the transmitter groups were positive to IgM.

In the confirmatory sample, obtained no more than 15 days after the first one during pregnancy, we determined the levels of specific anti-T. gondii IgG1-4 subclasses and IgA abs by inhouse ELISA, in addition to Peripheral Blood Mononuclear Cells (PBMCs) in vitro proliferation and cytokine production after specific stimulation when a sample was enough.

\section{Anti-T. gondii Antibody Detection and Avidity Test}

Anti-T. gondii total IgG/avidity test and class/subclass antibodies detection in serum were performed using previously validated indirect homemade ELISAs $(13,16)$. Briefly, STAg was coated overnight at $4^{\circ} \mathrm{C}$ in high binding plates (Maxisorp, Nunc Co, Rochester, NY) at $1 \mu \mathrm{g} / \mathrm{mL}$ in $0.1 \mathrm{M}$ carbonate buffer. Blocked with $1 \%$ bovine serum albumin in PBS-tween 20 and incubated with serum in the presence or not of $6 \mathrm{M}$ urea. Development was done with a commercial HRP-anti human IgG diluted 1:1000 in PBS-tween 20 and the substrate/chromogen solution with $\mathrm{O}$ phenylendiamine, until color development. Avidity percentage was calculated dividing the absorbance of the wells, treated with urea and untreated wells; cutoffs for avidity were as follows: below 51\% acute, 51-65\% gray zone, and above 65\% chronic (13). For IgG class/subclass, plates were coated overnight with $5 \mu \mathrm{g} / \mathrm{mL}$ of the STAg, blocked with 1\% BSA -PBS, sera diluted 1:500 for IgG, 1:250 for IgG1, and 1:125 for IgG2-4, and IgA in PBS-0.05\% Tween 20. Developed with peroxidase-labeled goat anti-human IgG or IgA, or biotinylated monoclonal abs against each IgG subclass, at optimal dilutions (16). For IgG subclasses, HRP-Streptavidin was used as final step, before the substrate/chromogen solution with $\mathrm{O}$-phenylendiamine was added; $0.1 \mathrm{~N}$ sulfuric acid was used to stop enzymatic activity in all cases (16). Finally, plates were read at $492 \mathrm{~nm}$. The results are expressed as the Reactivity Index (RI), that was calculated dividing the mean absorbance of duplicates of each sample by the cut-off value for each immunoglobulin (mean plus three standard deviations of six low, medium, and high negative controls). An RI $\geq 1.0$ was considered positive (13).

\section{Peripheral Blood Samples, Cell Culture and Proliferation Testing}

Approximately $5 \mathrm{~mL}$ of blood from participants, was obtained into EDTA-Vacutainer tubes. To obtain PBMCs, peripheral blood was subjected to Ficoll-Hypaque separation (GE Healthcare, Piscataway, NJ, USA). Then, PBMCs were labeled with $0.2 \mu \mathrm{M}$ CFSE (Molecular Probes/Invitrogen Detection Technologies, Eugene, OR) for $5 \mathrm{~min}$, the reaction was stopped by adding cold RPMI supplemented with $10 \%$ fetal calf serum (FCS) (Gibco, Carlsband, CA, USA). Cells were washed exhaustively with cold RPMI supplemented with $10 \%$ FCS, seeded into 96-well plates at a concentration of $1 \times 10^{6}$ cells $/ \mathrm{mL}$ and stimulated with $10 \mu \mathrm{g} / \mathrm{mL}$ of the STAg in triplicate, and then incubated at $37^{\circ} \mathrm{C}$ in $5 \% \mathrm{CO}_{2} / 95 \%$ air atmosphere, for $72 \mathrm{~h}$ for cytokine detection, and $120 \mathrm{~h}$ for cell proliferation assays. Concanavalin-A $[5 \mu \mathrm{g} / \mathrm{mL}]$ and medium alone were used as controls, positive, and negative, respectively. After the stimulation period, CFSE-labeled PBMCs were collected and stained with the following antibodies: CD3/APC-Cy7 (SK7), CD4/APC(OKT4), CD8/PERCP-Cy5 (RPA-T8), CD19/PE-Cy7 (HIB19) (BioLegend, San Diego, CA, USA). All samples were analyzed in a FACS-Aria flow cytometer (BD Biosciences, San Jose, CA, USA) using FlowJo (version 7) software (Tree Star Inc., Ashland, OR, USA). For the analysis, $1 \times 10^{4}$ events were collected. Relative proliferation index was calculated by dividing proliferation percentage of STAg-stimulated PBMCs by the proliferation percentage of non-stimulated PBMCs.

\section{Cytokine Detection in PBMCs Culture Supernatants}

Cytokine concentration in the supernatants obtained from PBMCs cultures, was quantified using the human inflammatory CBA kit, human Th1/Th2 CBA kit, and the human TGF$\beta 1$ Single Plex Flex set (BD Biosciences, San Jose, CA). The CBA analysis was performed with the FCAP Array Software v3.0 (BD Biosciences), from data obtained in a BD FACSAria flow cytometer (BD Biosciences). Production index for each cytokine tested was calculated dividing cytokine concentration from STAg-stimulated PBMCs by the cytokine concentration of the non-stimulated PBMCs.

\section{Data Analysis and Statistics}

Antibody reactivity, cytokine production, and proliferation indexes were compared between non-transmitter and transmitter groups, determining the statistical significance by comparison of ranks using the Mann-Whitney $U$-test and comparing proportions between groups using the Fisher's exact test. A $P$ $<0.05$ was considered significant. The GraphPad Prism version 7.0d for Macintosh, GraphPad Software, La Jolla California USA, www.graphpad.com, was used for these purposes.

\section{RESULTS}

As it can be seen in Table 1, those pregnant women who congenitally transmitted the parasite to their newborns generally presented a stronger and more variable humoral and cellular immune response than their non-transmitter counterparts. The exceptions were IgG1 abs and proliferation of $\mathrm{CD}^{+}$ lymphocytes, for which no difference was found between groups. $\operatorname{IgG} 2,3,4$ and $\operatorname{IgA}$ abs were present in a greater proportion of transmitters. Likewise, the proliferation of total lymphocytes, as well as of the $\mathrm{CD} 4^{+}, \mathrm{CD}^{+}$, and $\mathrm{CD} 19^{+}$subpopulations, was proportionally higher in the transmitter group (Table 1). Although we measured a broad range of cytokines such as IL$1 \beta$, IL-2, IL-4, IL-6, IL- 8 , IL-10, IL-12, TNF- $\alpha$, IFN- $\gamma$, and TGF- $\beta$ in culture supernatants from PBMCs stimulated with the STAg, we found a higher number of positive cases to TGF- $\beta$ in nontransmitter than in transmitter women we could test.

\section{DISCUSSION}

In this work, we measured IgG1-4, and IgA abs in serum, as well as in vitro PBMCs proliferation and cytokine production in 
response to STAg in infected women during pregnancy, and this response was analyzed as a function of parasite transmission to their newborns.

Herein, we found similar results of a previous work in which we did not encounter different proportions of positive mothers to IgG1 abs between groups (11). But, we found that IgG2-3 subclasses and IgA during pregnancy were more frequent and some of them at higher levels in transmitters than non-transmitters. Detection of any subclass before the end of pregnancy may reflect an anti-parasite immune response closer to the point of infection than those found at birth, especially for women with acute/subacute response (17-19). Interestingly, the four IgG subclasses are transported by the FcRn throughout the placenta since the first trimester $(20,21)$ and as it has been demonstrated by our group, each woman can develop a specific response in which one or two IgG subclasses predominate (16). Our data challenge the idea that maternal antiT. gondii IgG abs cross the placenta and protect the offspring from infections in utero and during early life (22). Moreover, FcRn is expressed by human microvasculature endothelial cells, facilitating a phenomenon that may be present in acquired toxoplasmosis too, facilitating body dispersion of the parasite (23). In general, our results showed that a more variable antibody response, might be directly or indirectly related to transmission of the parasite; if this is true, the immune response mediated by the maternal antibodies might be fetus-averse, not friend; at least, they seem non-protective.

Additionally, initiation and sustained strong T-cellmediated immunity is critical in preventing proliferation and dissemination of the parasite in acquired toxoplasmosis $(4,5)$. There is limited information about the maternal cell-mediated immunity during pregnancy against $T$. gondii in humans, and it has not been related to transmission (6-9). In this work, we found an increased proportion of specific anti STAg proliferation of total $\mathrm{CD} 4^{+}, \mathrm{CD}^{+}$, and $\mathrm{CD} 19^{+}$lymphocytes in the group of transmitter mothers. Holfheld et al. showed that the percentage of total $\mathrm{T}$ cells in mothers infected with the parasite is increased in peripheral blood, especially CD3 and CD8 positive cells, and consistent with our work, they suggested that mothers whose fetuses are infected, seem to have more important alterations in the percentages of the different subsets when compared to women whose fetuses are not infected; however, they searched for total, i.e., non- $T$. gondii specific, $\mathrm{CD}^{+}$and $\mathrm{CD} 8^{+}$cells (6). Another report by Fatoohi et al. showed that in women infected during pregnancy, $\mathrm{CD} 4{ }^{+}$cells are the main responders against the STAg (7). More recently, it has been demonstrated that in T. gondii primo-infected pregnant women, there is an increased proliferation of PBMCs, principally $\mathrm{CD}^{+}{ }^{+} \mathrm{CD} 4^{+}$(8) and showed an important role of $\gamma \delta \mathrm{T}$ lymphocytes producing IL-17 (9); nevertheless, in these studies the potential impact of mother's immune response on congenital transmission was not determined, but they focused in comparing the cellular immune response in parturient vs. non-pregnant women $(8,9)$.

Others have reported that $T$. gondii infected pregnant woman can produce IFN- $\gamma(5,7-9,24)$, but in this work we found transmitters as positive producers of this cytokine and additionally, lower producers of TGF- $\beta$. As it is well-known, this parasite induces high levels of IFN- $\gamma$ during infection as a result of early T-cell stimulation (25). IFN- $\gamma$ production promotes a robust inflammatory environment that limits infection in the mother's tissues (26). However, during pregnancy, there is evidence suggesting a paradoxical role of Th1 pro-inflammatory molecules, associating them to vertical transmission, or induction of damage to the offspring in murine models: IFN- $\gamma$ inhibition during pregnancy has been associated with a lower proportion of infected fetuses in mice $(24,27,28)$. This was explained by the "Trojan horse" hypothesis, in which parasite dissemination depends on the ability to infect highly motile dendritic cells and monocytes/macrophages recruited by the pro-inflammatory environment to the site of infection, and spread into several tissues, including the brain, even if the parasite infection is acquired orally $(29,30)$. It has been demonstrated that STAg can induce the expression of MIF in an IFN- $\gamma$-dependent manner, and furthermore, MIF is able to induce ICAM-1 expression $(31,32)$. Interestingly, ICAM-1 mediates cellular adhesion of T. gondii infected monocytes to human trophoblasts in vitro (32), and has also been described as MIC2 ligand, a T. gondii adhesin (33). In general, the Th1 environment orchestrated by IFN- $\gamma$, can attract infected cells or even induce the expression of pro-inflammatory proteins that may facilitate maternalfetal interface parasite direct adhesion, probably facilitating its infection, and passage throughout the placenta (31). Together with an overproduction of Th1 pro-inflammatory molecules, a poorly regulated environment is detrimental for pregnancy. TGF- $\beta$ is an important Th 1 antagonist cytokine, which plays an important role in the maintenance of pregnancy. Interestingly, T. gondii infection inhibits TGF- $\beta$ production at the fetalmaternal interface in mice, provoking adverse outcome (34). Moreover, TGF- $\beta$ can modulate mothers' immune response during pregnancy, by increasing Treg differentiation (35) and it has been reported that $T$. gondii infection during pregnancy in mice reduces splenic and placental $\mathrm{CD} 4{ }^{+} \mathrm{CD} 25^{+}$regulatory $\mathrm{T}$ cells (36). More recently, Zhao et al. showed that T. gondiiinfected pregnant mice treated with TGF- $\beta$ improved adverse pregnancy outcomes, while TGF- $\beta$ neutralization produced serious hemorrhage, more dilated uterine spiral arteries, and decreased local Treg cell numbers (37); these data are in agreement with our results and may suggest that an increased inflammation induced by $T$. gondii could promote congenital transmission in a poorly regulated environment due to low TGF- $\beta$ production, favoring systemically abs production and lymphocytes proliferation that may be involved in dissemination and transmission of the parasite.

Only one mother of the non-transmitter group had circulating parasite DNA, as demonstrated by $\mathrm{qPCR}$, so the parasite burden in blood did not seem to account for higher transmission risk. Since we recruited mothers who had abs of low/gray zone avidity, our results could be reflecting the acute response that accompanies parasite proliferation and placental crossing, but even in this case, it can be stated that the response which is protective for the adult host, is ineffective to prevent vertical transmission. Our results only demonstrate a potential relation between maternal immune profile during pregnancy and T. gondii vertical transmission, but since they are congruent 
with results in animal models and previous indirect results in humans mentioned above, we think that a rather strong and non-regulated maternal immune response during pregnancy is directly or indirectly related to T. gondii congenital transmission, which deserves more investigation.

\section{Limitations of the Study}

The main limitation of this study was the small number of cases, which hindered our ability to have stronger statistical support. Studies of Treg cells and cytokines not included in the present study could add important information about this complex form of toxoplasmosis.

\section{AUTHOR CONTRIBUTIONS}

DC and RF-D conceived experimental design and wrote the project to which these data belong. JM-G recruited part of the pregnant women studied. FG-C, YF-G, IC-S, LO-A, and HL-P conducted the laboratory experiments. FG-C and

\section{REFERENCES}

1. Maldonado YA, Read JS. Diagnosis, treatment, and prevention of congenital toxoplasmosis in the United States. Pediatrics (2017) 139:20163860. doi: 10.1542/peds.2016-3860

2. Dubey JP, Jones JL. Toxoplasma gondii infection in humans and animals in the United States. Int J Parasitol. (2008) 38:1257-78. doi: 10.1016/j.ijpara.2008.03.007

3. Olariu TR, Remington JS, McLeod R, Alam A, Montoya JG. Severe congenital toxoplasmosis in the United States: clinical and serologic findings in untreated infants. Pediatr Infect Dis J. (2011) 30:1056-61. doi: 10.1097/INF.0b013e3182343096

4. Yap GS, Sher A. Cell-mediated immunity to Toxoplasma gondii: initiation, regulation and effector function. Immunobiology (1999) 201:240-7. doi: 10.1016/s0171-2985(99)80064-3

5. Denkers EY, Gazzinelli RT. Regulation and function of T-cell-mediated immunity during Toxoplasma gondii infection. Clin Microbiol Rev. (1998) 11:569-88.

6. Hohlfeld P, Forestier F, Marion S, Thulliez P, Marcon P, Daffos F. Toxoplasma gondii infection during pregnancy: T lymphocyte subpopulations in mothers and fetuses. Pediatr Infect Dis J. (1990) 9:878-81.

7. Fatoohi AF, Cozon GJN, Greenland T, Ferrandiz J, Bienvenu J, Picot S, et al. Cellular immune responses to recombinant antigens in pregnant women chronically infected with Toxoplasma gondii. Clin Vaccine Immunol. (2002) 9:704-7. doi: 10.1128/cdli.9.3.704-707.2002

8. Prigione I, Chiesa S, Taverna P, Ceccarelli R, Frulio R, Morandi F, et al. $\mathrm{T}$ cell mediated immune responses to Toxoplasma gondii in pregnant women with primary toxoplasmosis. Microb Infect. (2006) 8:552-60. doi: 10.1016/j.micinf.2005.08.008

9. Alves Silva JL, Rezende-Oliveira K, da Silva MV, Gómez-Hernández C, Crema Peghini B, Silva NM, et al. IL-17-expressing $\mathrm{CD}^{+}$and $\mathrm{CD} 8^{+} \mathrm{T}$ lymphocytes in human toxoplasmosis. Mediat Inflamm. (2014) 2014:573825. doi: 10.1155/2014/573825

10. Rezende-Oliveira K, Silva NM, Mineo JR, Rodrigues Junior V. Cytokines and chemokines production by mononuclear cells from parturient women after stimulation with live Toxoplasma gondii. Placenta (2012) 33:682-7. doi: 10.1016/j.placenta.2012.05.013

11. Cañedo-Solares I, Galván-Ramírez MdlL, Luna-Pastén H, Rodríguez Pérez LR, Ortiz-Alegría LB, Rico-Torres CP, et al. Congenital toxoplasmosis: specific IgG subclasses in mother/newborn pairs. Pediatr Infect Dis J. (2008) 27:46974. doi: 10.1097/INF.0b013e31816591df
DC reviewed and analyzed the data. FG-C wrote the paper. IC-S, LO-A, RF-D, JM-G, and DC revised it. All authors read the final version of the manuscript and approved it for publication.

\section{FUNDING}

This work was supported in part by CONACyT (grant number 139721) and the Instituto Nacional de Pediatría (060/2011). FG-C is a Cátedra CONACyT Research Fellow. FG-C, RF-D, LO-A, IC$\mathrm{S}$, and DC are SNI-CONACyT Fellows. YF-G had a postdoctoral fellowship from CONACyT, Mexico.

\section{ACKNOWLEDGMENTS}

The authors are thankful to Valeria Gómez-Toscano for clinical follow-up of congenital toxoplasmosis cases, as well as Lizbeth Xicotencatl-García for her excellent technical assistance.

12. Caballero-Ortega H, Castillo-Cruz R, Murieta S, Ortíz-Alegría LB, CalderónSegura E, Conde-Glez CJ, et al. Diagnostic-test evaluation of immunoassays for anti-Toxoplasma gondii IgG antibodies in a random sample of Mexican population. J Infect Dev Ctries. (2014) 8:642-7. doi: 10.3855/jidc.3858

13. Cañedo-Solares I, Ortiz-Alegría LB, Figueroa-Damián R, Bustos-Bahena ML, González-Henkel H, Calderón-Segura E, et al. Toxoplasmosis in pregnancy: determination of IgM, IgG and avidity in filter paper-embedded blood. $J$ Perinatol. (2009) 29:668-72. doi: 10.1038/jp.2009.79

14. Rico-Torres CP, Figueroa-Damián R, López-Candiani C, Macías-Avilés HA, Cedillo-Peláez C, Cañedo-Solares I, et al. Molecular diagnosis and genotyping of cases of perinatal Toxoplasmosis in Mexico. Pediatr Infect Dis J. (2012) 31:411-3. doi: 10.1097/INF.0b013e318241f564

15. Gómez-Toscano V, Linares-López KA, Arce-Estrada GE, Figueroa-Damian R, Barrios Bautista DM, Hernández-Luengas L, et al. Toxoplasmosis congénita en el valle de México. Resultados de una serie de casos (congenital toxoplasmosis in the Valley of Mexico. Results of a case series). Acta Pediatr Mex. (2018) 6: 321-33. doi: 10.18233/APM39No6pp321-3331730

16. Cañedo-Solares I, Gómez-Chávez F, Luna-Pastén H, OrtizAlegría LB, Flores-García Y, Figueroa-Damián R, et al. What do anti-T. gondii IgA and IgG subclasses in human saliva indicate? Parasite Immunol. (2018) 40:12526. doi: 10.1111/pim. 12526

17. Mankarious S, Lee M, Fischer S, Pyun KH, Ochs HD, Oxelius VA, et al. The half-lives of IgG subclasses and specific antibodies in patients with primary immunodeficiency who are receiving intravenously administered immunoglobulin. J Lab Clin Med. (1988) 112:634-40.

18. Ee TY, Singh M, Yap EH. The determination of anti-Toxoplasma gondii antibodies in different IgG subclasses of human sera by the enzyme-linked immunosorbent assay (ELISA). Southeast Asian J Trop Med Public Health (1989) 20:71-9.

19. Santana SS, Silva DAO, Vaz LD, Pirovani CP, Barros GB, Lemos EM, et al. Analysis of IgG subclasses (IgG1 and IgG3) to recombinant SAG2A protein from Toxoplasma gondii in sequential serum samples from patients with toxoplasmosis. Immunol Lett. (2012) 143:193-201. doi: 10.1016/j.imlet.2012.02.008

20. Malek A. Role of IgG antibodies in association with placental function and immunologic diseases in human pregnancy. Expert Rev Clin Immunol. (2014) 9:235-49. doi: 10.1586/eci.12.99

21. Dancis J, Lind J, Oratz M, Smolens J, Vara P. Placental transfer of proteins in human gestation. Am J Obstet Gynecol. (1961) 82:167-71. doi: 10.1016/s0002-9378(16)36111-7 
22. Ortiz-Alegría LB, Caballero-Ortega H, Cañedo-Solares I, Rico-Torres CP, Sahagún-Ruiz A, Medina-Escutia ME, et al. Congenital toxoplasmosis: candidate host immune genes relevant for vertical transmission and pathogenesis. Genes Immun. (2010) 11:363-73. doi: 10.1038/gene.2010.21

23. Ortiz-Alegría LB, Cañedo-Solares I, Vadillo-Ortega F, Castillo-Castrejón M, Correa D. Potential of HMEC-1 line and HUVEC primary culture cells to study the neonatal IgG Fc receptor in vitro. Am J Immunol. (2016) 12:1-9. doi: 10.3844/ajisp.2016.1.9

24. Pfaff AW, Abou-Bacar A, Letscher-Bru V, Villard O, Senegas A, Mousli M, et al. Cellular and molecular physiopathology of congenital toxoplasmosis: the dual role of IFN- $\gamma$. Parasitology (2007) 134:1895-902. doi: $10.1017 /$ s0031182007000200

25. Yarovinsky F. Innate immunity to Toxoplasma gondii infection. Nat Rev Immunol. (2014) 14:109-21. doi: 10.1038/nri3598

26. Mor G, Aldo P, Alvero AB. The unique immunological and microbial aspects of pregnancy. Nat Rev Immunol. (2017) 17:469-82. doi: 10.1038/nri.2017.64

27. Shiono Y, Mun H-S, He N, Nakazaki Y, Fang H, Furuya M, et al. Maternal-fetal transmission of Toxoplasma gondii in interferon- $\gamma$ deficient pregnant mice. Parasitol Int. (2007) 56:141-8. doi: 10.1016/j.parint.2007.01.008

28. Abou-Bacar A, Pfaff AW, Georges S, Letscher-Bru V, Filisetti D, Villard O, et al. Role of NK cells and gamma interferon in transplacental passage of Toxoplasma gondii in a mouse model of primary infection. Infect Immun. (2004) 72:1397-401. doi: 10.1128/iai.72.3.1397-1401.2004

29. Courret N. CD11c- and CD11b-expressing mouse leukocytes transport single Toxoplasma gondii tachyzoites to the brain. Blood (2006) 107:309-16. doi: 10.1182/blood-2005-02-0666

30. Coombes JL, Charsar BA, Han SJ, Halkias J, Chan SW, Koshy AA, et al. Motile invaded neutrophils in the small intestine of Toxoplasma gondii-infected mice reveal a potential mechanism for parasite spread. Proc Natl Acad Sci USA. (2013) 110:E1913-22. doi: 10.1073/pnas.1220272110

31. Ferro EAV, Mineo JR, Ietta F, Bechi N, Romagnoli R, Silva DAO, et al. Macrophage migration inhibitory factor is up-regulated in human firsttrimester placenta stimulated by soluble antigen of Toxoplasma gondii, resulting in increased monocyte adhesion on villous explants. Am J Pathol. (2008) 172:50-8. doi: 10.2353/ajpath.2008.070432
32. Pfaff AW, Georges S, Abou-Bacar A, Letscher-Bru V, Klein J-P, Mousli M, et al. Toxoplasma gondii regulates ICAM-1 mediated monocyte adhesion to trophoblasts. Immunol Cell Biol. (2005) 83:483-9. doi: 10.1111/j.1440-1711.2005.01356.x

33. Barragan A, Brossier F, Sibley LD. Transepithelial migration of Toxoplasma gondii involves an interaction of intercellular adhesion molecule 1 (ICAM-1) with the parasite adhesin MIC2. Cell Microbiol. (2005) 7:561-8. doi: 10.1111/j.1462-5822.2005.00486.x

34. Xu X, Zhang J, Zhan S, Li Z, Liu X, Zhang H, et al. TGF- $\beta 1$ improving abnormal pregnancy outcomes induced by Toxoplasma gondii infection: Regulating NKG2D/DAP10 and killer subset of decidual NK cells. Cell Immunol. (2017) 317:9-17. doi: 10.1016/j.cellimm.2017.04.004

35. Zare-Bidaki M, Assar S, Hakimi H, Abdollahi SH, Nosratabadi R, Kennedy D, et al. TGF- $\beta$ in Toxoplasmosis: friend or foe? Cytokine (2016) 86:29-35. doi: 10.1016/j.cyto.2016.07.002

36. Ge YY, Zhang L, Zhang G, Wu JP, Tan MJ, Hu W, et al. In pregnant mice, the infection of Toxoplasma gondii causes the decrease of $\mathrm{CD}^{+} \mathrm{CD}^{+} 5^{+}$-regulatory T cells. Parasite Immunol. (2008) 30:471-81. doi: 10.1111/j.1365-3024.2008.01044.x

37. Zhao M, Zhang H, Liu X, Jiang Y, Ren L, Hu X. The effect of TGF- $\beta$ on treg cells in adverse pregnancy outcome upon Toxoplasma gondii infection. Front Microbiol. (2017) 8:901. doi: 10.3389/fmicb.2017.00901

Conflict of Interest Statement: The authors declare that the research was conducted in the absence of any commercial or financial relationships that could be construed as a potential conflict of interest.

Copyright (c) 2019 Gómez-Chávez, Cañedo-Solares, Ortiz-Alegría, Flores-García, Luna-Pastén, Figueroa-Damián, Mora-González and Correa. This is an open-access article distributed under the terms of the Creative Commons Attribution License (CC $B Y)$. The use, distribution or reproduction in other forums is permitted, provided the original author(s) and the copyright owner(s) are credited and that the original publication in this journal is cited, in accordance with accepted academic practice. No use, distribution or reproduction is permitted which does not comply with these terms. 